\title{
Kirjavarastoinnin uusia tuulia Kuopio 6 -konferenssissa
}

\author{
Johanna Lilja, Johanna Vesterinen, Liisa Savolainen
}

Kuopio-konferenssit ovat perinteisesti koonneet yhteen kirjojen varastoinnista ja varastokirjastopalveluista kiinnostunutta kirjastoväkeä eri maista. Kuudes Kuopio-konferenssi järjestettiin tänä vuonna Baselissa ja sen ohjelmaan kuului vierailu robotisoituun varastokirjastoon, Kooperative Speicherbibliothekiin. Suomesta konferenssiin osallistuivat apulaiskirjastonjohtaja Liisa Savolainen ja palvelujohtaja Johanna Lilja Kansalliskirjastosta sekä Varastokirjaston entinen kirjastonjohtaja Pentti Vattulainen ja nykyinen kirjastonjohtaja Johanna Vesterinen.

Varastointiratkaisut ovat monissa kirjastoissa päivänpolttavia. Julkaisutoiminnan digitalisoituminen, paine säästää julkisen sektorin kuluissa ja tarve muuttaa kokoelmatiloja opiskelijoiden työ- ja ryhmätyötiloiksi ohjaavat yliopistokirjastoja etsimään tiloja muualta. Digitalisaatio vähentää painetun aineiston käyttöä, muttei kokonaan poista sitä, sillä kaikkea aineistoa ei tekijänoikeuksien vuoksi voi saattaa sähköisenä asiakkaille. Siksi pääsääntöisesti halutaan säästää ainakin yksi kappale kutakin painettua julkaisua, myös ulkomaisten käyttökokoelmien kappaleista.

\section{Taloudellisia ja hallinnollisia ratkaisuja}

Varastointikulujen säästämiseksi tyypillisiä ratkaisuja ovat etävarastointi suurten kaupunkien ulkopuolella ja yhteiskäyttöiset varastotilat. Ratkaisut voivat olla alueellisia tai kansallisia. Alueellista yhteistyömallia edusti konferenssin vierailukohde Kooperative Speicherbibliothek, joka tarjosi tilaa ja aineiston välityspalveluita kuudelle Pohjois-Sveitsin yliopistokirjastolle. Alueellinen yhteisvarasto on toteutettu myös Kataloniassa. Lisäksi hajautetutta varastointiyhteistyötä pilotoidaan parhaillaan Pohjois-Saksassa.

Yhdysvalloissa on syntynyt moninaisia palveluita. Esimerkiksi Center for Research Libraries (CRL) syntyi Chicagoon kymmenen Keskilännen tutkimuskirjaston yhteiseksi kaukopalvelu-, vaihto- ja varastokeskukseksi jo 1940-luvulla. Nykyisin se palvelee kansallisesti ja kansainvälisesti yli 200 kirjastoa. Se toimii voittoa tekemättömänä järjestönä, jonka jäsenet maksavat oman osuutensa laitoksen kuluista. Jäsenillä on äänioikeus, ja valtaa käyttää hallitus. Varastoinnin ja kaukopalvelun lisäksi CRL tarjoaa myös digitointi- ja lisensiointipalveluja.

Puhtaasti liiketoimintamalliin perustuvaa ratkaisua esitteli konferenssissa Jeremy Suratt, joka edusti yritystä Iron Mountain Incorporated. Yritys toimii kaikkiaan 53 maassa ja tarjoaa monimuotoisia arkistointi- ja varastointifasiliteetteja kaikille tahoille, jotka tuottavat säilytettävää aineistoa: tiedostoja, kuvia, arkistoaineistoa, filmimateriaalia - vain muutamia mainiten. Yrityksen perusajatus on tarjota luotettavaa, turvallista ja organisoitua "tilaa" kaikille sitä tarvitseville. Tilalla tarkoitetaan fyysistä, arkistonkaltaista ympäristöä, sekä immateriaalista tilaa. Toimintamallin tavoitteena on yhtäältä edesauttaa lähettäjäorganisaatiota (kuten kirjastoa) vapauttamaan tilaa muuhun toimintaan, mutta vastata muun muassa aineistojen säilyttämisen turvallisuudesta, vaatimista olosuhteista ja löydettävyydestä. Yrityspalvelujen osalta konferenssiyleisöä kiinnosti kysymys, mitä kokoelmille tapahtuu, jos yritys menee konkurssiin, mutta tähän ei saatu selkeää vastausta.

Julkisesti rahoitettua ja hallinnoitua mallia edusti The UK Research Reserve (UKRR), jota rahoittaa Higher Education Funding Council for England (HEFCE). UKRR varastoi tieteelli- 
siä lehtiä. Hallitus koostuu tiedeyhteisön edustajista. Dokumenttien toimittamista hallinnoi British Library.

Useisiin varastoihin oli liitetty digitointipalveluja. Varsinkin lehtiartikkelit toimitettiin yleensä asiakkaille sähköisessä muodossa.

\section{Mitä pieni edellä...}

Suomessa Varastokirjasto on jo vuodesta 1989 tarjonnut toimivan keskitetyn ratkaisun kirjastojen poistaman aineiston varastointiin ja kaukopalvelukäyttöön. Suomen varastokirjastomalli on toiminut esimerkkinä monille maille. Samaan toimintatapaan ja rahoitusmalliin ei muualla ole pästy, mutta keskeisimpiä toiminnan elementtejä on voitu onnistuneesti soveltaa.

Vastaaviin kirjastoihin verraten ainutlaatuiseksi suomalaisen varastokirjastotoiminnan tekee, että varastokirjastotoiminta on lailla ja asetuksella säädetty; kirjastolla on siis määritellyt lakisääteiset tehtävät. Kirjaston toiminta on julkisrahoitteista kuuluen valtion budjetointiin. Lisäksi kirjaston asema opetus- ja kulttuuriministeriön alaisena virastona on mahdollistanut toiminnan suunnitelmallisen kehittämisen yhdessä kirjastosektoreiden kanssa. Kirjaston toimintaa ohjaa opetusja kulttuuriministeriön asettama johtokunta, joka on koottu erityisesti kirjastojen välisen yhteistyön kehittämiseksi. Johtokunnan tehtävänä on huolehtia kirjaston yleisestä kehittämisestä ja päättää toiminnan suuntaviivoista sekä toimia yhteistyöelimenä kirjastoihin päin.

Esimerkkinä Varastokirjaston ja kirjastojen aktiivisesta yhteistoiminnasta on vuonna 2015 laadittu Varastokirjastokirjaston kokoelmapoliittinen linjaus, jonka tekemiseen osallistui edustajia jokaiselta kirjastosektorilta. Kirjastot ovat sitoutuneet noudattamaan laadittuja ohjeita ja näin on pystytty kehittämään kokoelmanhallintaa.

Kokoelmapolitiikan ohella olennainen osa suomalaista varastokirjastotoimintaa on toimiva kaukopalvelu. Kolmenkymmenen vuoden aikana kaukopalvelutoiminta on kehittynyt vastaamaan asiakkaiden tarpeisiin. Varastokirjasto on ollut
Suomen suurin kaukopalvelukeskus vuodesta 1996 alkaen. Palvelun maksuttomuus ja kaukopalvelun toimitusnopeus ovat edelleen niitä seikkoja, joissa Suomi on edelläkävijämaa.

\section{Speicherbibliothekin avainluvut}

- 2,2 miljoonaa nidettä

- tilaa 2,8 miljoonalle niteelle

- aineiston haku varastosta 6 minuuttia

- 7 työntekijää (aina vähintään 3 henkilöä töissä yhtä aikaa)

- erilaisia kuljetusvaihtoehtoja eri kirjastoihin; kuljetus kirjastoihin 2-48 tuntia

- kirjalainoja toimitetaan kuukaudessa 4 000-5 000

- jäljenteitä toimitetaan kuukaudessa 400-700

\section{Robotiikka kirjaston palveluksessa}

British Libraryn Andrew Appleyard johdatti jo ensimmäisenä konferenssipäivänä yleisön robotiikkaratkaisujen pariin esitellessään johtamaansa etävarastoa Yorkshiressa sijaitsevassa Boston Spassa. Sieltä robotiikalla toimiva noutopalvelu toimittaa tilatut julkaisut 48 tunnissa Lontooseen. Järjestely on mahdollistanut $30 \%$ säs̈stöt tila- ja palvelukustannuksissa. Yksikköön on sijoitettu myös digitointitoimintaa.

Konferenssivieraille tarjottiin mahdollisuus tutustua robotiikkaratkaisuihin lähemmin perjantaipäivän vierailulla, joka tehtiin Kooperative Speicherbibliothekiin. Noin tunnin ajomatkan päässä Baselista, Büro-nimiseen kylään, hyvin maaseutumaiseen ympäristöön oli rakennettu modernia teknologiaa edustava varastokirjasto, joka otti vastaan kokoelmia kuudesta jäsenkirjastosta.

Speicherbibliothekin prosessi on tehokas ja monelta osin automatisoitu. Julkaisut otetaan vastaan ihmistyönä. Ensimmäiseksi ne puhdistetaan imurointi- ja harjauskoneessa, jotta varastoon ei kulkeutuisi pölyä. Tarvittaessa teh- 


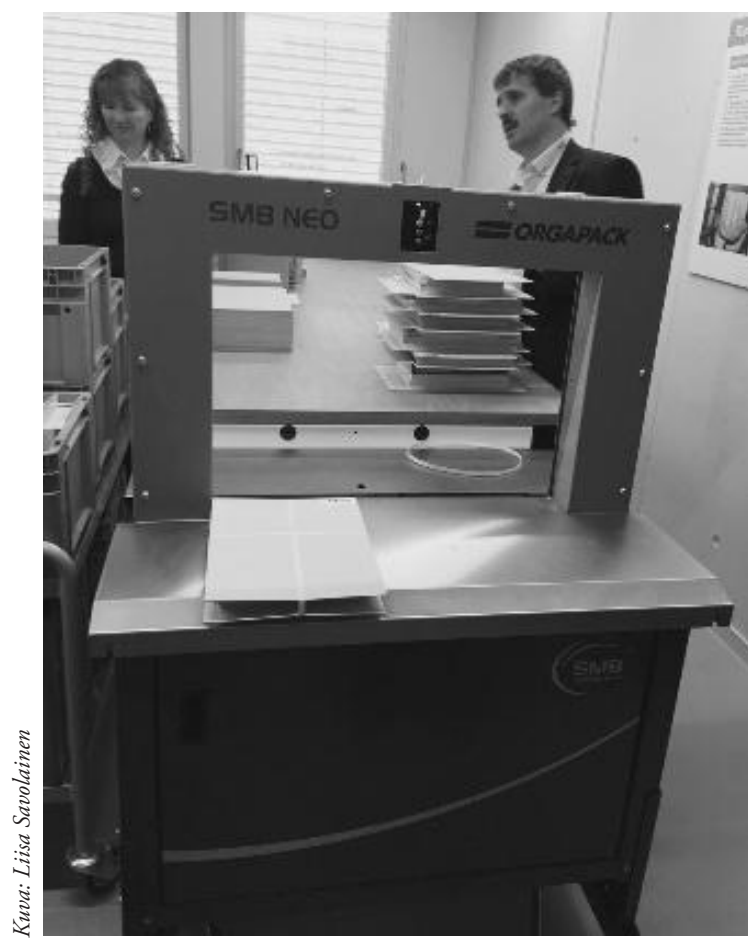

Säilytettävät lehdet sijoitetaan hapottomien pahvikansien väliin. Kannet kiinni solmivaa vannekonetta esitteli konferenssivieraille toimitusjohtaja Mike Märki, joka oli ollut mukana hankkeessa suunnittelun käynnistymisestä alkaen ja oli ilmeisen ylpeä onnistuneesta tuloksesta.

dään pieniä korjaustoimenpiteitä, jos sidokset ovat huonokuntoisia. Lehdet järjestetään pahvikansien väliin ja vannekone sujauttaa kannet kiinni muovinauhalla. Kirjat pakataan muovilaatikoihin, joilla on oma viivakoodinsa. Tämän jälkeen työ siirtyy roboteille, jotka etsivät varastosta paikan kullekin laatikolle. Robotit myös noutavat järjestelmästä tulleet tilaukset ja toimittavat ne hihnalle, jonka päässä taas ihminen jatkaa työtä toimittaen julkaisun asiakkaalle. Jäsenkirjastoille kirjat toimitetaan kärryihin lastattuna kuriiripalvelun välityksellä. Speicherbibliothek toimittaa myös muualle kaukolainoja: kirjat lähetetään postitse ja artikkelit digitaalisina jäljenteinä, jotka digitoidaan paikan päällä.

Tilat on rakennettu tehokkaiksi ja säilytyksen kannalta optimaalisiksi. Lämpötila vaihtelee vuodenajasta riippuen $7-25$ asteen välillä, mutta muutokset ovat korkeintaan $+/-2$ astetta 48 tunnissa. Samoin kosteus pyritään pitämään vakaana eli $45 \%$ :ssa, ja muutos saa olla vain $+/-5 \%$ yksikköä 48 tunnissa. Paloturvallisuuden takaa alhainen $14 \%$ happipitoisuus. Näissä ihmiselle verrattain epämukavissa oloissa työskentelevät vain robotit. Siivousta ei tarvitse tehdä säännöllisesti, koska tiloihin viedään vain puhtaita kirjoja.

\section{Varastoinnin tulevaisuus Suomessa}

Kuopio 6 -konferenssi antoi paljon aihetta pohtia myös kotimaisen julkaisuvarastoinnin tulevaisuutta. Varastokirjaston palvelua on perinteisesti pidetty varsin toimivana. Valtionhallinnon näkökulmasta Varastokirjasto on kuitenkin pieni yksikkö ja tästä syystä hallitusohjelman taustalla olevien Virsu ja Kehu -hankeselvitysten perusteella Varastokirjasto on esitetty liitettäväksi Kansalliskirjastoon. Varastokirjaston liittäminen Kansalliskirjastoon merkitsisi muutoksia Varastokirjastolakiin ja Yliopistolakiin, mistä syystä ratkaisun asiassa tekee eduskunta. Poliittinen päätöksentekoprosessi on tätä kirjoitettaessa vielä kesken.

Tällä hetkellä Varastokirjasto on toimiva malli. Se on pohjana tuleville suunnitelmille, mikäli Varastokirjasto yhdistetään Kansalliskirjastoon. Mahdollinen yhdistäminen tulee tarkoittamaan investointia uudisrakennukseen, joka puolestaan tarjoaisi tilaisuuden varastoinnin tilojen ja tekniikan muuttamiseen sekä myös toimintakonseptin uudistamiseen. Onkin käynnistettävä keskustelua siitä, millaista palvelua asiakaskirjastot haluavat ja tarvitsevat 2020-luvun lopulla. Miten painettujen aineistojen käyttö ja varastointi muuttuu? Miten aineistoja välitetään asiakaskäyttöön viiden tai kymmenen vuoden päästä? Suunnittelussa pitäisi pystyä visioimaan ja innovoimaan, jotta mahdollisesta yhdistämisestä saadaan kaikki hyöty. Lopputulema ei voi olla vain se, että valtionhallinnossa on yksi virasto vähemmän, vaan muutoksella tulee mahdollistaa myös painettujen aineistojen varastointipalvelun uusi taso.

Kuopio-konferenssi tarjosi paljon aineksia 


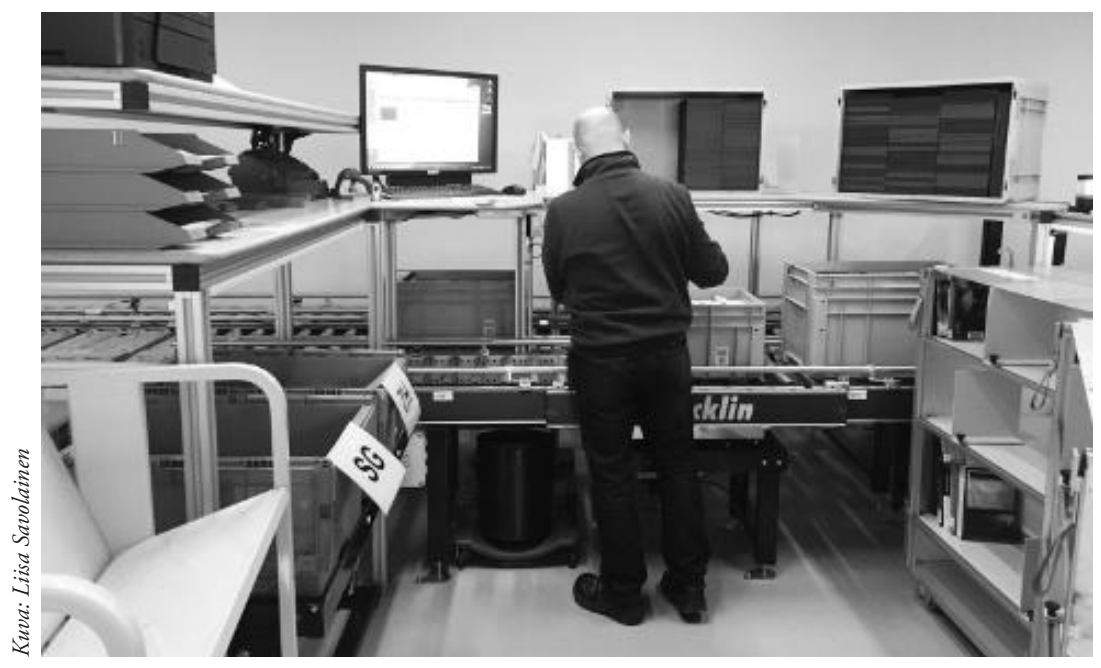

Robottien hihnalle asettamat laatikot tulevat palvelupisteeseen, jossa ne käsitellään ja pakataan ihmistyönä.

suunnittelulle, päädytäänpä Suomessa mihin ratkaisuun tahansa. Konferenssin keskeinen anti oli, että painetun aineiston varastoiminen on jatkossakin tärkeä asia, jolla turvataan tiedon saatavuutta myös sähköisen julkaisukulttuurin aikana. Esitelmissä tuli esiin myös painetun kirjan tärkeys: varsinkin humanisti tarttuu edelleen mielellään kirjaan ja tarvitsee työhönsä myös vanhempaa aineistoa. Hyvin toimiva keskitetty painetun aineiston varasto ei ole digitalisaation vastakohta, vaan pikemminkin sen mahdollistaja.

\section{Lähteet:}

Andrew Appleyard: "Thinking out of the box" The British Library approach to storage. https:// www.ub.unibas.ch/fileadmin/redaktion/ub/wiru eberuns/veranstaltungen/kuopio6/0-1-Box_ Appleyard_20180314.pdf

Santi Balagué: GEPA, the Cooperative Repository in Catalonia CSUC, Manage https://www.ub.unibas.ch/ fileadmin/redaktion/ub/wirueberuns/veranstaltungen/ kuopio6/1-2-1803Kuopio6GEPA.pdf

Center for Research Libraries http://www.crl.edu/ about

Jeremy Suratt: Access, Environment, and Cost how do you decide what's right for your collections? https://www.ub.unibas.ch/fileadmin/redaktion/ub/ wirueberuns/veranstaltungen/kuopio6/2-2-IronMountain_Suratt_20180315.pdf
Varastokirjaston yhdistäminen Kansalliskirjastoon. https://api.hankeikkuna.fi/asiakirjat/b85de7e0-39f843ec-9c11-6d0fad3f0f $12 / 1$ fec9f35-ad4a-434b-be7e319efeecb818/JULKAISU_20180119085206.pdf)

Johanna Vesterinen: De-Duplication-is it worth it? The National Repository Library Finland. https://www. ub.unibas.ch/fileadmin/redaktion/ub/wirueberuns/ veranstaltungen/kuopio6/6-1-De-duplication Vesterinen_20180313.pdf

What is UKRR? http://www.ukrr.ac.uk/what/default. aspx

Robert Zepf \& Olaf Eigenbrodt: Speicherverbund Nord: a Regional Print Archiving Cooperative in Northern Germany. https://www.ub.unibas.ch/fileadmin/redak tion/ub/wirueberuns/veranstaltungen/kuopio6/6-2Speicherverbund-Nord_Zepf-Eige nbrodt_20180315. pdf

\section{Tietoa kirjoittajista:}

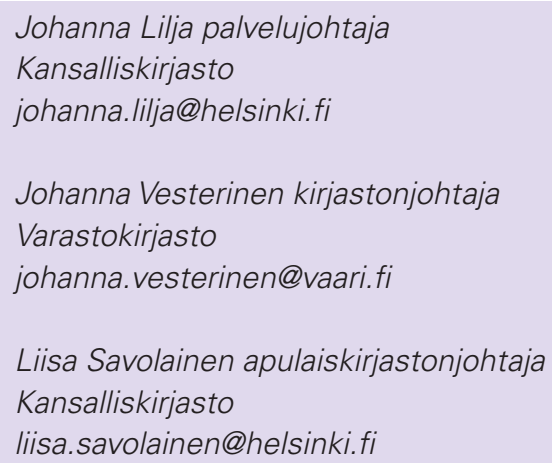

